FELIPE CORVALÁN T. Arquitecto Universidad de Chile

\section{Tradiciones, Traducciones y Transferencias}

\begin{abstract}
El presente número de revista de Arquitectura plantea una aproximación crítica al desarrollo de E nuestra disciplina en el contexto chileno. Un objetivo complejo y probablemente pretencioso, pero que lejos de intentar revelar verdades absolutas o posturas definitivas, espera contribuir a un debate abierto y por definición inconcluso. Un ámbito de discusión marcado por las incertidumbres: ¿es posible hablar de "arquitectura chilena" o se trata más bien de "arquitectura hecha en Chile"?; ¿̇qué elementos distinguen o podrían distinguir a esta producción?; ¿̇cuáles son los desafíos y oportunidades asociadas al desarrollo futuro de la disciplina en el contexto local? Interrogantes que de una $u$ otra manera han sido abordadas por el conjunto de artículos que dan forma a esta edición.
\end{abstract}

La presencia recurrente de la arquitectura chilena en publicaciones especializadas y encuentros internacionales configura un escenario que hace aún más necesaria la reflexión en torno a los alcances de esta producción. Un estado de situación que además permite poner en evidencia la brecha existente entre un desarrollo sostenido de obras y la ausencia de una elaboración teórica o discursiva que piense, cuestione y valore las distintas dimensiones de este desarrollo. En esta dirección, tomando como referencia el concepto de "campo" propuesto por Pierre Bourdieu, que no sólo remite al objeto-obra como fuente de análisis, hemos intentado abrir y distinguir la trama relacional dentro de la cual es posible pensar a la arquitectura chilena, al menos parcialmente.

La valoración del paisaje y el medioambiente, la presencia de la arquitectura como fuente de memoria histórica, el diálogo entre tradición y contemporaneidad, el vínculo entre el quehacer arquitectónico y las demandas socioculturales del país, son algunas de la temáticas abordadas por los autores. Trabajos que creemos logran ampliar los mecanismos habituales de aproximación y análisis de la arquitectura chilena, centrada generalmente en rasgos estéticos y/o formales de un conjunto de obras particularmente reducidas.

En el primero de los dos números de la revista dedicados a la producción arquitectónica de nuestro país, los artículos de Aguilar y Solís inician el debate problematizando en torno a las características que hoy definen a la arquitectura chilena contemporánea. Un acercamiento que también permite reconocer las "deudas pendientes" de la producción local: la ausencia de un pensamiento crítico articulado y el predominio de proyectos privados en desmedro del fortalecimiento de un espacio público participativo y de calidad. Espacio público que también es abordado por el texto de lturra, recurriendo a nuevas metodologías que permitan re-significar nuestra relación con el ámbito de lo urbano.

En el caso de Maulen, Eliash y Weil, el interés por la enseñanza de la arquitectura y su vinculación con las demandas sociales nos permite reflexionar en torno al rol que ha desempeñado el arquitecto en la construcción del llamado proyecto-país. Una mirada consciente de la inscripción histórica de la arquitectura que también podemos encontrar en los proyectos de título de Francisco Cruz y Victoria Opazo, promoviendo espacios de conmemoración y valorando nuestro patrimonio cultural.

De esta manera, historia, sociedad y contemporaneidad, se entrelazan para dar comienzo a una reflexión sobre la arquitectura chilena. Una reflexión que creemos debe ser permanente actualizada, para de esta manera dar respuesta a los cambios y transformaciones culturales que experimenta nuestro país. 